\title{
UNA NUEVA ESPECIE DE DECAZYX (RUTACEAE) DE TABASCO Y VERACRUZ
}

\section{FERNANDO CHIANG**}

\section{RESUMEN}

Se describe una nueva especie de Decazyx (D. esparzae, Rutaceae) de Tabasco y Veracruz. El nuevo taxon es un árbol pequeño, de la selva tropical del Sureste de México. La otra especie conocida de este género es $D$. macrophyllus de Honduras.

\section{ABSTRACT}

A new species of Decazyx (D. esparzae, Rutaceae) from Tabasco and Veracruz is described. The new taxon is a small tree of the rain forests of southeastern Mexico. The only other known species in this genus is D. macropbyllus from Honduras.

Decazyx esparzae Chiang, nov. sp.: a Decazyx macropbyllo Pittier et Blake foliis base attenuata in petiolo alato angustatis et ovario nudo differt.

Arbol de 8-15 m de alto, con hojas alternas, cartáceo-coriáceas, elípticas a obovadas, de $10-30 \mathrm{~cm}$ de largo por $6-12 \mathrm{~cm}$ de ancho, con numerosas glándulas translúcidas distribuidas en toda la lámina, margen ligeramente ondulado, revoluto, a veces irregularmente dentado, ápice cortamente acuminado a obruso a redondeado o emarginado, base de la hoja cuneada, la lámina desvaneciéndose gradualmente en un pecíolo angostamente alado de $1-1.5 \mathrm{~cm}$ de largo, unido a una base engrosada pulviniforme de 5-9 mm de largo, nervaduras secundarias principales 14-18 pares. Inf'orescencia una panícula racemiforme de $7-32 \mathrm{~cm}$ de largo, flores blancas, agrupadas en glomérulos espaciados sobre el eje floral, subtendidas por brácteas deltoides, pedicelos de $1 \mathrm{~mm}$ de largo, lóbulos del cáliz 5 , imbricados, de $1 \mathrm{~mm}$ de largo, ampliamente ovados, con borde eroso, pétalos 5, elíptico-obovados, glabros, glandulares, de $3.5 \mathrm{~mm}$ de largo y $1.5 \mathrm{~mm}$ de ancho; estambres 10 , unidos en la base, alternadamente desiguales en longitud, 5 cortos y 5 largos, filamentos aplanados, ciliados, con algunas glándulas del mismo tipo que las de los pétalos; ovario glabro, 5-locular, descansando

* Trabajo aceptado para su publicación en Octubre de 1982.

** Departamento de Botánica. Instituto de Biología, UNAM. 


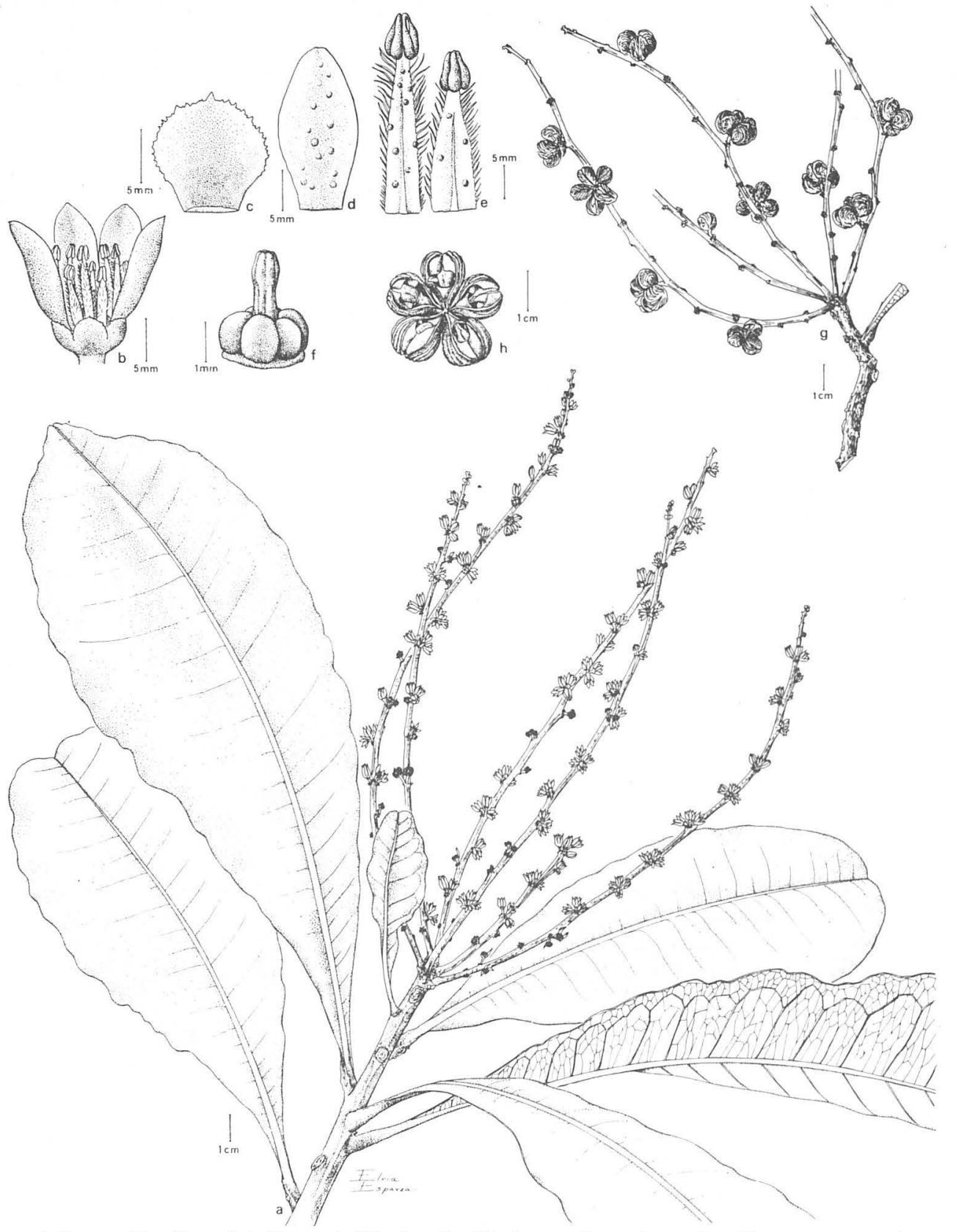

a) Rama Florífera, b) Flor, c) Sápalo, d) Pétalo, e) Estambres, f) Gineceo, Zamudio et al. 322 ; g) Rama con frutos, h) Fruto, Zamudio et al. 359. 
sobre un disco grueso, estilo más corto que los estambres, estigma globoso, con 5 crestas; fruto de 1.5 folículos ovados de $7 \mathrm{~mm}$ de largo, unidos solamente en la base, rugosos; semillas de color beige claro, aplanadas lateralmente, rodeadas de un endocarpo cocleado de $6 \mathrm{~mm}$ de largo, libre, amarillento, pergamentáceo-coriáceo, bilobado.

Tipo: Tabasco: Agua Blanca, Municipio de Macuspana, ladera caliza con vegetación de selva alta perennifolia, 15 de mayo de 1982, S. Zamudio R., A. Suárez y A. Guadarrama 322 (Holótipo: MEXU; isótipo: CSAT).

Paratipos: Tabasco: Municipio de Teapa: Cerro del Coconá, las grutas del Coconá, cerca de Teapa, 6 de abril de 1980, C. Cowan 2893 (MEXU); 12 de junio de 1982, S. Zamudio R., A. Suárez y A. Guadarrama 359 (MEXU); Veracruz: Municipio de Minatitlán, $13.7 \mathrm{~km}$ al E de La Laguna, sobre terracería a Uxpanapa, luego $7 \mathrm{~km}$ al $\mathrm{N}$ sobre camino nuevo (no completo) a Belisario Domínguez. Lat. $17^{\circ} 20^{\prime} 30^{\prime \prime} \mathrm{N}$, Long. $94^{\circ} 23^{\prime} \mathrm{W}$. Elevación $130 \mathrm{~m}, 15$ de abril de 1981, T. Wendt, E. Lott, F. Chiang e I. Navarrete 3186 (MEXU).

Esta especie crece en terrenos calizos, en ocasiones con topografía cárstica, en selva alta perennifolia. El otro representante del género es Decazyx macrophyllus Pittier et Blake, de Honduras, el cual posee un pecíolo no alado, engrosado tanto en la base como en el ápice y el ovario y el fruto pubescentes.

El nombre de esta especie está dedicado a la Sra. Elvia Esparza, autora de numerosas ilustraciones científicas, tanto de animales como de vegetales, de una calidad artística y nitidez difíciles de igualar, autora asimismo de las ilustraciones de este artículo.

\section{AGRADECIMIENTOS}

Se agradece a los Biólogos Clark Paul Cowan y Sergio Zamudio el haber proporcionado material de herbario; al Dr. Thomas L. Wendt, transporte y material de herbario. 